\title{
Study on the Compositions and the Value of Knowledge-Based GDP in China
}

\author{
Xue Zhang, Wei Song \\ School of Public Affairs, University of Science and Technology of China, Hefei, China \\ Email: lena1125@mail.ustc.edu.cn
}

How to cite this paper: Zhang, $X$. and Song, W. (2018) Study on the Compositions and the Value of Knowledge-Based GDP in China. Open Journal of Social Sciences, 6, 246-256.

https://doi.org/10.4236/jss.2018.61018

Received: December 7, 2017

Accepted: January 27, 2018

Published: January 30, 2018

Copyright $\odot 2018$ by authors and Scientific Research Publishing Inc. This work is licensed under the Creative Commons Attribution International License (CC BY 4.0).

http://creativecommons.org/licenses/by/4.0/

(c) (i) Open Access

\begin{abstract}
Nowadays, as the development of knowledge economy and innovation, it is an inevitable trend to add the knowledge-based GDP into the national economy accounting system. The knowledge-based GDP is made of the intellectual property products, innovative capital, marketing assets and human capital. This paper suggests that the knowledge-based GDP should be included in the scope of national accounts, which will bring about the total expansion and great improvement of China's GDP accounting and promote the development of China's knowledge-intensive industries. At the same time, it will also become an important basis for the government's macro management and micro decision-making.
\end{abstract}

\section{Keywords}

Knowledge Economy, Knowledge-Based GDP, Intellectual Property Products, System of National Accounting

\section{Introduction}

Paul A. Samuelson, a U.S. economist and Nobel laureate in economics, regarded the gross domestic production (GDP) as one of the greatest inventions of the twentieth century, and he ever said: if not when accounting for aggregating measures such as GDP, policymakers can only drift in a cluttered ocean of data, and GDP with its related information acts as a beacon to help planners drive their economies toward the key goals [1]. As the most important measurement in national economy accounting, GDP plays a very important role. Currently, the national accounting system commonly used in various countries around the world is the system of national accounting 1993 (SNA 1993). However, in some countries with more advanced statistics capacity such as the United States, Aus- 
tralia and the Netherlands, the new accounting system, system of national accounting 2008 (SNA 2008), has been started. The typical feature of the new version, SNA 2008, is the expansion of intellectual property products and its accounting system and presenting the current trend of knowledge economy. However, so far, China has not accounted the intellectual property products in the scope of GDP. According to the latest statistics, the condition of innovation in China is full of vitality and the level of innovation continues to rise. Based on the increasing proportion of knowledge economy in China's economic development, GDP accounting should include the economic activities of the knowledge-based industry as an important measurement of a country's economic developing. Exploring the knowledge-based GDP and proposing to integrate the knowledge-based GDP into the scope of the national economy should become the hot issues in the current national economy research.

\section{GDP and Knowledge-Based GDP}

\subsection{The Definition of GDP}

After the Second World War, the system of national accounts gradually becomes the mainstream in the national accounts of various countries and accumulated rich experience in the continuous practice and revision. Its development has gone through four stages, from the initial SNA 1953 version to the later SNA 1968, SNA 1993 and the latest version, SNA 2008, which also underwent many times during the revision and the accounting system tends to be completed now.

SNA is a set of internationally accepted standard recommendations for economic activity that based on strict accounting principles on economics and presents them as a set of complete concepts, definitions, classifications and accounting rules that include the measures such as an internationally accepted standard for projects, gross domestic product which is the most commonly used indicator of economic performance. SNA refers to the total market value of the final products and services created by the residents of a country within a certain period of time (usually within one year), which is the balance of the total social product value after deducting the value of the intermediate product, that is, the new creation of the period and the total value of wealth [2]. The main functions of GDP are to measure the size of the economic power and the level of poverty in a country or region, to analyze the scale and potential growth of the economy in a country.

Many countries now commonly use GDP as their national accounts and there are three types of accounting: production, distribution and expenditure. The production method is obtained by subtracting the intermediate consumption from the gross output value of each industry. The distribution is to calculate the final product value from the perspective of factor income which is the sum of individual laborers' income, state taxes, corporate profits and depreciation. Expenditures is drawn from the sum of resident consumption expenditure, government consumption expenditure, gross fixed asset formation and net exports 
[3]. Among the three accounting methods, the expenditure is the most commonly used one, and in the national economy accounting, it is an internationally accepted important indicator of the final demand, which consists of three major needs: consumer demand, investment demand and import and export demand [4]. In the expenditure method of accounting, consumer demand is also the final consumer spending, including consumer spending and government consumer spending. Investment demand is called the total capital formation, including total fixed capital formation and inventory increase. Net export demand is called the goods and Net exports of services, that is to say, exports of goods and services decreasing the balance of imports of goods and services. The national disposable income in the national economy accounting is an internationally accepted important indicator of macro-income distribution, which consists of the disposable income of the three major economic activities, namely disposable income of residents, disposable income of enterprises and government disposable income. The above indexes are all the more important analytical tools in the national accounting.

With the deepening of the reform and the development of the socialist market economy, the degree of integration between China's economy and the world economy has been further developed. The atmosphere of economy in China has become much more complicated with more and more influencing factors and severe challenges. It is more important, difficult and arduous than ever to analyze the domestic economic situation scientifically in such a context by objectively comparing the international economies and accurately grasping the economic trends. Therefore, the economic statistics as an important basis for the analysis of the domestic economic situation and the comparative analysis of the international economy have been applied widely. At the same time, it is also becoming increasingly important to understand and correctly use economic statistics.

\subsection{The Definition of Knowledge-Based GDP}

The knowledge-based GDP, also known as the intelligent GDP, refers to the sum of the wealth created by the knowledge-based industry. In a national economy accounting, GDP is an important measurement of the overall development of the national economy in a country. Knowledge-based GDP is the development of a comprehensive response to knowledge-related industry and it is a special product of the knowledge economy in the 21st century.

Intellectual property is an inevitable product of the development of science and technology and it is also the social productivity to a certain stage. Developments in related technical fields have made the enterprises with knowledge assets occupying a favorable position in the increasingly fierce market competition and have created the miracles of economic growth. All of these make knowledge assets being an important driving force for economic growth and enterprise development in various countries. Knowledge assets as the most important re- 
source in the knowledge-based economy have become the focus of the whole world.

Since the 1980s, with the development of knowledge-based industry, people have paid much more attention to the relation of knowledge in economy than others. In 1985, the Japanese scholar used the concept of knowledge-based value in the book The Value of Knowledge Revolution to predict that the society must be a knowledge-based society in the future, and he believes that the value created by human intelligence and wisdom will be the main asset of the future society due to the changes in technology, resources, environment and population [5]. In 1986, the British scholar Forrest, in the book High-tech Society, made a clear definition of high-tech economy due to a series of influences on the economic development brought by the new scientific and technological revolution.

By the 1990s, the concept of knowledge economy or knowledge-based economy appeared in a great variety of books and reports. In 1990, the relevant research institutes in the United Nations put forward the concept of knowledge economy and defined it the nature of new form of economy. With the rapid development of knowledge-based economy in the 21st century, the most important factor of economic growth has been transformed into mental activity, and the industrialization of knowledge has increasingly become an important part of a country's soft power [6].

On April 11, 2012, the report on Intellectual Property and the U.S. Economy: Industrial Focus jointly released by the U.S. Department of Commerce, Bureau of Economic Statistics and the United States Patent and Trademark Office showed that innovation is the result of the U.S. economy growing and the key driving factor of competitiveness [7]. The granting and protection of intellectual property rights are the key to promote innovation and creativity and they are the basic elements of free competition and market economy for enterprises.

Due to the current situation, it is necessary to conduct a scientific analysis of the related activities of each product by accurately analyzing the economic contribution rate, innovation expenditure, marketing and human capital of the various intellectual property product factors in the production and transaction sectors in the knowledge economy environment, and finally the national accounts, that is, knowledge-based GDP accounting will be a reasonable record of its presentation. The accounting of knowledge-based GDP will provide a basis for better macro-economic analysis and economic decision-making in order to understand the essence of GDP after adding the value of intangible capital such as intellectual property products, innovation spending, marketing assets and human capital.

\section{The Compositions of Knowledge-Based GDP}

According to the appendix of SNA 2008 and its research topics, this paper argues that the knowledge-based GDP should be composed of the contribution rate of intellectual property products to the economy, the input and output of 
innovation in $\mathrm{R} \& \mathrm{D}$, marketing assets and human capital.

\subsection{The Compositions of Intellectual Property Products}

As described in the appendix to SNA 2008 prepared by the United Nations, the European Commission, the Organization for Economic Co-operation and Development and the International Monetary Fund, SNA 2008 has made new additions to the assets formerly known as intangible assets in the accounting process, renamed it a more intuitive as intellectual property products. On this basis, SNA 2008 specifically put forward specific forms of intellectual property products, including: research and development $(\mathrm{R} \& \mathrm{D})$; mineral exploration and valuation; computer software and databases; entertainment, literary and artistic originals and other intellectual property products [8]. Thus, under realistic conditions, intellectual property products that can be described and counted include research and development, exploration and valuation of mineral resources, computer software and databases, entertainment, literary and artistic originals.

\subsubsection{Research and Development (R \& D)}

In SNA 2008, intellectual property products are an important component of fixed assets classification, which not only include the original intangible assets, but also make the expands and supplements of them. Comparing SNA 2008 with SNA 1993, we can see that the main content of the SNA 2008 extension is: R \& D expenditures that were originally treated as intermediate consumption in the Production Account are now included in the intellectual property products asset range, as a fixed capital formation treatment, and included in the capital account. In the meantime, SNA 2008 also proposes to include research and development expenditures as intellectual property products under fixed assets in the balance sheet accounts and the original non-production assets patent entities into the research and development under the production of assets of the fixed assets [9]. Research and development occupy an important place in the national economy of a country, however, unlike the real economy, research and development are easily overlooked. Research and development are the crystallization of wisdom, only after a large amount of knowledge input will it be possible to obtain output. Therefore, it is an important manifestation of knowledge-based economy and it is indisputably included in the national economy.

\subsubsection{Mineral Exploration and Valuation}

SNA 2008 renamed mineral exploration to mineral exploration and assessment and added the assessment and reassessment costs for commercial exploration to the valuation proposed in the SNA 1993 accounting system when accounting for mineral exploration expenditures [10]. Exploration and assessment of mineral deposits require a great deal of knowledge and wisdom, and they need to be developed with countless sets of scientific, effective and operational solutions and strategies. Therefore, it is also an important part of knowledge-based GDP. 


\subsubsection{Computer Software and Database}

SNA 2008 replaced the original computer software with computer software and database and further being subdivided into two categories: computer software and database. Because without the database management system (DBMS), it is impossible to develop a computer database, and DMBS itself is a computer software, in the SNA 2008 accounting system, all the databases belong to the asset range, while SNA 2008 also proposed to have all in more than one year of validity data stored in the database identified as a fixed asset. Computer software and databases are the typical products of intellectual property. Even if some computer software and databases are temporarily unable to fully participate in economic activities, their input as knowledge and technology should be included in the scope of national economy accounting, highlighting the impact of human knowledge and intellectual activities on the economy contributions.

\subsubsection{Original Entertainment, Literature and Art}

For the first time, SNA 2008 classifies entertainment, literary and artistic originals as intellectual property rights (IPR) products and specifically presents specific ways of handling originals and replicas. Intangible intellectual property products such as entertainment, literature and art originations are the fruits of the development of human wisdom and civilization and they bring together a great deal of manpower and intelligence.

\subsection{Innovation Spending}

The research agenda of the SNA 2008 Appendix 4-D3 extends the boundaries of fixed assets and provides a special note on innovation. In the SNA 2008 expansion for fixed asset boundaries, although $\mathrm{R} \& \mathrm{D}$ covers part of the innovation process, it does not include much of what the manufacturing and engineering departments do. These departments may also be responsible for identifying potential new products and submitting them to the $\mathrm{R} \& \mathrm{D}$ department to enable the $\mathrm{R} \& \mathrm{D}$ department to develop the scientific knowledge behind it. In addition, other expenses may occur before a new product is launched, including marketing research to determine the demand for new products and marketing expenses to market the product, all of which are part of the innovation. Therefore, putting forward the innovation separately is to meet the needs of the development timely. The innovation expenditure has occupied a large proportion of the enterprise's R \& D expenditure.

\subsection{Marketing Assets}

Marketing assets include brand name, header, trademark, logo, and domain name. In the era of knowledge economy, brand economy has become the label. Marketing is the key driver of brand value. The companies invest greatly in the establishment and supporting of brands through advertising, sponsorship, and other means to create a positive image among their clients, to gain market share accordingly. However, SNA treats marketing assets as non-productive assets and 
expenditures during their creation as intermediate expenditures, and these assets are only included in the balance sheet when they are sold, which is apparently unreasonable. Marketing is the most important economic activity of an enterprise. Brand names, prefaces, trademarks, logos, and domain names are unique and cannot be copied and belong to the knowledge assets of an enterprise. Therefore, marketing assets should be included in knowledge-based GDP.

\subsection{Human Capital}

Human resources correspond to human capital, but these two cannot be the same. In the national accounts system, removing the staff training required to bring new products to market, innovation spending has nothing to do with innovating. As a result, innovative spending largely excludes human capital investment. However, the human input is the main investment in most production processes, and the value of this investment depends largely on the amount of knowledge that brought into the production process by manpower, therefore, human capital should be included in the knowledge GDP.

All in all, in an age when the knowledge economy is dominant, all economic activities related to knowledge should be included in the national economy accounting system of a country. In reality, it is necessary to carry out the accounting measurements of intellectual property products, innovation, marketing assets and human capital, and it will also be the inevitable trend of the development of the times.

\section{Intellectual Property Products Being Included in the Scope of SAN in the Developed Countries}

With the development of knowledge economy, intellectual property has increasingly become an important part of a country's soft power. The new SNA 2008 proposed amendments to the classification and accounting of IP products and formally placed them as assets in the scope of national accounting.

After the official release of SNA 2008, developed countries with more advanced statistical system and more developed data bases have started to implement or plan to implement new international standards. Some countries estimated the impact of their statistics on their GDP based on changes in the accounting rules of the new version of SNA 2008. According to the research report (2015): after the release of the new SNA 2008, the United States estimates that in 2012 and the U.S. GDP grew 3.6\% according to the latest revised national income and production account statistics. In 2012, Canada released revised GDP data based on the latest accounting system, which showed an annual average increasing of about $2.4 \%$ of GDP in 2007-2011. Australia has treated R \& D spending as a fixed asset since 2009, resulting in a $1.45 \%$ increase in Australia's GDP in 2008. Although EU countries officially started implementing SNA 2008 in September 2014, the Netherlands has already started to revise GDP before that. According to the results of the announcement, the GDP of the Netherlands 
increased by $3.0 \%$ in 2010 due to the adoption of the latest rules [11].

In 2013, the United States leads in adopting the new accounting standards in SNA 2008 around the world. The most important point was that intellectual property products were included as assets in the economic accounting system. Once implemented, this has an important impact on the U.S. macro-economic indicators. Preliminary findings from a comprehensive survey of US national income and product accounts NTPAs released by the United States Bureau of Economic Analysis (BEA) at the end of 2013 show that after the United States readjusted its GDP statistics, and intellectual property products such as entertainment, original literary and artistic expenditures, were included in the statistics, and the U.S. GDP increased nearly $3 \%$. Studying the economic contribution of intellectual property intensive industries, the proportion of intellectual property products in the GDP of the United States was $40 \%$, which virtually dampened the negative impact brought by the instability of the U.S. in the meantime, it highlighted the success of the U.S. economic restructuring. The United States has successfully shifted from an industrial dependent into an era of knowledge and information based on intellectual resources. In this adjustment, the Bureau of Economic Analysis has expanded its asset boundaries as defined in SNA 2008 and incorporated R \& D expenditures as a fixed capital formation into its national accounts and it is included in the balance sheet as intellectual property products under fixed assets. At the same time, it estimates the loss of R \& D assets and accounts for depreciation of fixed assets. However, the United States is the country with the largest R \& D spending in the world, which virtually expands the total U.S. GDP.

As the world's largest economy country, the technology-intensive and service-oriented industries in the United States have an important impact on the development of the global economy [12]. However, in the previous national accounts, expenditure on social and economic activities such as R \& D, entertainment, and literary origin, which reflected the knowledge economy and innovation and development, were recorded as intermediate consumption, which was not conducive to study the development of such industries and to the formulation and improvement of relevant industrial policies. Therefore, the comprehensive adjustment conducted by the U.S. government this time has enlarged and revised the border of assets and has adapted itself to the inherent needs reflecting objectively the new economic development and new changes in the industrial structure. This is not the whitewashing or irrigation of the country itself of the economic development. The U.S. adjustment will encourage other countries to follow suit and speed up the transformation of the global economic development model.

Prior to this, most countries, including China, adopted the international standard SNA 1993 for statistical calculation, which made us seriously underestimate the value of knowledge products and did not accurately reflect the true contribution of knowledge to the economy. We cannot fully and objectively un- 
derstand and grasp the macroscopic structure of economic development. Japan began to start implementing the new version of SNA 2008 in 2016, and China will implement the new version of the accounting rules and adopt it partially in 2017 according to the specific conditions.

\section{Conclusions and Suggestion}

In today's world, the trend of knowledge economy development and innovation growth has been very clear. According to the 2015 Global Innovation Index report, China is full of vitality in innovation and ranks in the seventh in the same level countries [13]. Innovation continues to promote the rapid economic growth in China and China has achieved rapid economic growth in recent years. At the same time, R \& D and creative industries represented by the knowledge economy have also made great progress [14]. Therefore, China should draw lessons from the research results of other countries and start with the practical development. 1) It should begin to carry out $R \& D$, capitalization, entertainment, literary and art expenditure and other intellectual property products into accounting system as soon as possible; 2) It also should be hurry to research innovation expenditure, marketing assets and human capital and accounting studies to explore the possibility of new accounting methods applicable in the country. Especially in recent years, the proportion of China's R \& D investment in GDP has reached the level of the moderately developed countries, and the number of intellectual property has been growing rapidly. The capability of using intellectual property has been gradually increasing, and the contribution of intellectual property-intensive industries to the economy has risen steadily [15]. Under this realistic background, China should incorporate knowledge GDP more into the national economy, and include the intellectual property products, innovation expenditure, marketing assets and human capital into the scope of GDP statistics accurately. This will help the country to adjust its economic structure and promote the development and innovation of China's economic restructuring [11].

This article suggests that it will have very important theoretical significance to the research on the knowledge GDP of China. Firstly, it will help to improve the accounting quality of statistical data and improve China's national economic accounting system. Secondly, it will help to improve the international comparability of statistical data and link it with the internationally recommended accounting system. Finally, it will improve the economic applicability of statistics. The integration of knowledge GDP into China's total GDP accounting will not only expand the total GDP, but also optimize its proportion structure in the future as the proportion of knowledge industries expansion. This paper believes that it will be of great practical significance to study the accounting of intellectual property products, innovation, marketing assets and human capital in China. It can truly reflect the changes in industrial structure, especially the share of knowledge-intensive industries in the entire national economy. Obviously, it is of great significance for understanding the current situation of the industrial 
structure in a country or region and the law of its development and changes, formulating the correct industrial development policies and guiding the sound development of the industrial structure. Certainly, it can truly reflect the changes in the demand structure, especially the intellectual property products, the share of consumption, capital formation and net exports in aggregate demand, which is not hard for the future to truly reflect the changes in the investment structure. Due to the concern and advancement on knowledge industry accounting issues, it will also greatly encourage governments, enterprises, $\mathrm{R} \& \mathrm{D}$ institutions and other organizations to increase their investment in science and technology research and development, and promote the transformation of economic development with technological innovation.

In the era of knowledge economy, highlighting the important contribution made by the knowledge-based industries to the national economy in the GDP accounting is not only the inevitable choice of a country in the increasingly fierce global economic competition, but also the economic and social development themselves. Overall, the study of knowledge GDP will bring about the total expansion and great improvement of China's GDP accounting, which will also become an important basis for the macro-management and micro-decisionmaking of the government in China, so as to promote the development of the knowledge-intensive industries and increase the protection of intellectual property rights and assets management. Besides, it will encourage enterprises to improve the efficiency of R \& D spending, promote business investment in research and development, industrial upgrading and enterprise restructuring, strengthen the understanding of the development of cultural industries and promote the development of creative and cultural industries, and improve total factor productivity so as to achieve high-quality growth.

\section{References}

[1] Zhao, Y. (2001) GDP: One of the Great Inventions of the 20th Century. Statistical Research, No. 52, 53.

[2] The United Nations (2012) System of National Accounts 2008. China Statistics Press, Beijing, 687-689.

[3] Gao, M., Xu, J. and Li, J. (2006) Principles of National Economic Accounting and Practice in China. China Renmin University Press, Beijing, 5-19.

[4] Zheng, X. (2011) Study on Quarterly GDP Calculation Methods of Some Major Countries. Statistical Research, No. 28, 37.

[5] Xiao, Y. (2000) The Trend of Global Knowledge Economy Development. Science Press, Beijing, 17-18.

[6] Cooke, P. and Leydesdorff, L. (2006) Regional Development in the KnowledgeBased Economy: The Construction of Advantage. The Journal of Technology Transfer, 31, 5-15. https://doi.org/10.1007/s10961-005-5009-3

[7] http://qyj.saic.gov.cn/llyj/201507/t20150721_159246.html.2015-11-25

[8] Xu, X. (2013) Comparative Study on Some Important Indicators of China's National Economic Accounting with Related Statistics. World Economy, 147.

[9] Li, J. (2015) The Study on Accounting Problems of Intellectual Property Products. 
Ph.D. Thesis, Jiangxi University of Finance and Economics, China.

[10] Gao, M. (2013) New Features of 2008 SNA: Some Reflections. Statistical Research, No. 30, 9 .

[11] Song, X. (2015) Understand China's GDP. Peking University Press, Beijing, 108109.

[12] Zeng, W. (2014) The Main Contents, Effects and Revelations of the Latest Adjustment on GDP Accounting in USA. Statistical Research, No. 31, 13.

[13] Global Innovation Index (2015) http://www.wipo.int/econ_stat/zh/economics/gii/

[14] Ni, H. (2014) Capitalization of R \& D Spending and Analysis of Its Impact on GDP and Economic Structure. Studies in Science of Science, No. 32, 1167.

[15] Song, X. (2007) Some Issues and Statistics about China's GDP. Economic Research Journal, No. 8, 24. 